\title{
Acoustic Investigation of Textile Fabrics
}

\section{Akustična raziskava tekstilnih tkanin}

\author{
Original scientific article/lzvirni znanstveni članek \\ Received/Prispelo 10-2020 • Accepted/Sprejeto 10-2020 \\ Corresponding author/Korespondenčna avtorica: \\ Prof. Dr. Dr. Andrea Ehrmann \\ E-mail: andrea.ehrmann@fh-bielefeld \\ ORCID: 0000-0003-0695-3905
}

\begin{abstract}
Why is it possible to distinguish between different textile fabrics by just touching them and moving your hand over them and listening to the sound? Particularly for high-quality woven fabrics, e.g. used for tailor-made suits, it is quite common that the dressmaker listens to the sound as their hand rubs the fabric. Can this approach be translated into a technical measurement? What could a sound analysis tell us about the fabric properties? As a first simple approach, we used a record player to rotate different cotton fabrics, and tested fine tips from diverse materials, such as plastic pipettes, pens, glass tips, etc. Our results show clear differences between the textile fabrics, which can be attributed to different yarn, knitted or woven structures. While the rotational mode of investigation impedes fully automated fast Fourier transform (FFT) evaluations, our first results suggest developing this promising method further.

Keywords: sound analysis, woven fabrics, knitted fabrics, hairiness, surface structure, roughness.
\end{abstract}

\section{Izvleček}

Zakaj je mogoče razlikovati med različnimi tekstilnimi tkaninami tako, da samo premikate roko po njej in poslušate zvok? Predvsem za visokokakovostne tkanine, npr. take, ki se uporabljajo za obleke po meri, je zelo pogosto, da krojačica posluša zvok svoje roke, ki se premika po površini blaga. Ali je mogoče ta pristop tehnično izmeriti in kaj bi nam takšna zvočna analiza lahko povedala o lastnostih tkanine? Kot prvi preprost pristop smo s pomočjo predvajalnika gramofonskih plošč vrteli različne bombažne tkanine in preizkušali fine konice iz različnih materialov, kot so plastične pipete, pisala, steklene konice itd. Naši rezultati kažejo jasne razlike med tkaninami, ki jih lahko pripišemo različnim prejam, pletenim ali tkanim strukturam. Medtem ko rotacijski način preiskave ne omogoča popolnoma samodejne ocene hitre Fourierjeve transformacije (FFT), so naši prvi rezultati spodbudni za nadaljnji razvoj te obetavne metode. Ključne besede: analiza zvoka, tkanine, pletiva, kosmatost, površinska struktura, hrapavost

\section{Introduction}

Textile fabrics are often used for sound absorption or acoustic insulation and investigated for this purpose by many research groups [1-5]. Some groups also work on developing acoustic sensors embedded in yarns or fabrics [6].

Only recently has the issue been addressed whether acoustic investigations of textile fabrics, i.e. per- forming an analysis of the sound created by frictional movement along their surfaces $[7,8]$, could reveal information about the fabrics. Wang et al. studied the friction sounds created by woven fabrics from natural fibres rubbing on each other and found frequency-dependent loudness, averaging over time [9]. Loudness was also the parameter investigated in some other studies, e.g. by Yi and Cho, examining different woven fabrics $[10,11]$. Afterwards, 
Yi et al. as well as Kim et al. added subjective pitch, clearness and sharpness to the loudness, and found correlations with different mechanical properties, as measured with a Kawabata KES-FB $[12,13]$. The same sound generator, rubbing two fabrics under a defined load against each other, was also used to investigate warp-knitted and weft-knitted fabrics in terms of loudness and loudness range $[14,15]$. A comprehensive study on knitted and woven fabrics with a focus on water repellent, vapor permeable fabrics was carried out by Park and Cho, comparing acoustic and mechanical parameters [16].

A slightly different approach was chosen by Yosouf $e t$ al. [17]. They developed an instrument which follows the trajectory of a moving arm along the side of the body, in this way for the first time not following a linear trajectory, i.e. moving two fabrics against each other not exactly along warp or weft direction, but along a bent line. Evaluation of the acoustic measurements concentrated on the amplitude, as in most previous studies.

Here, another approach is chosen. Instead of averaging over large areas by investigating textile-textile friction, we perform an acoustic analysis using fine tips from different materials, enabling time- and spatially resolved sound examination. In this way, it is generally possible to acoustically count warp and weft densities in woven fabrics and similar numbers in warp and weft knitted fabrics.

\section{Materials and methods}

All textile fabrics under examination in this study consisted of $100 \%$ cotton. Table 1 gives an overview of the fabric parameters.

An L3865 record player (Lenco, Nuth, Netherlands) was used to rotate the samples cut to fit the dimension of the turntable. A 130D20 microphone (PCB Piezotronics) attached to an SN 23697 AD-converter

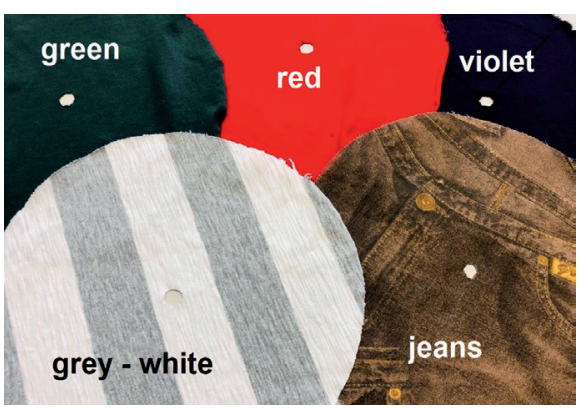

a)

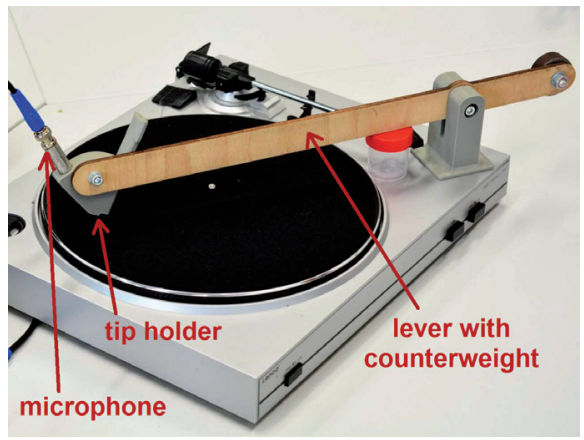

b)

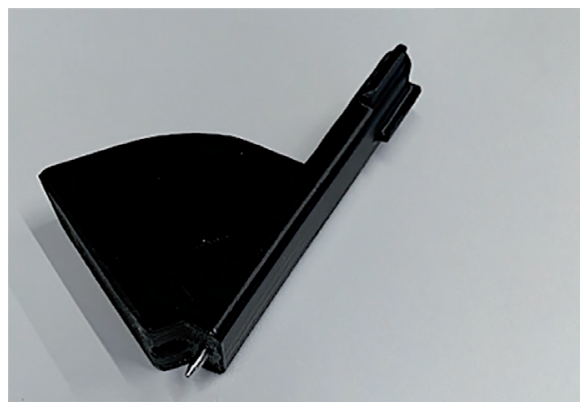

c)

Figure 1: a) Cut samples under examination; b) Measurement setup with the tip holder and inserted microphone (attached to the blue connector) mounted on a lever, which allows it to carefully touch the rotating textile fabric; c) Ballpoint pen refill placed in the tip holder

Table 1: Fabric parameters of the samples under investigation

\begin{tabular}{|l|l|c|c|c|c|}
\hline Name & Structure & Thickness $(\mathrm{mm})$ & $\begin{array}{c}\text { Areal weight } \\
\left(\mathrm{g} / \mathrm{m}^{2}\right)\end{array}$ & $\begin{array}{c}\text { Courses/cm } \\
\text { Ends/cm }\end{array}$ & $\begin{array}{c}\text { Wales } / \mathrm{cm} \\
\text { Picks/cm }\end{array}$ \\
\hline Green & weft knitted & 0.80 & 181 & 18 & 13 \\
\hline Red & weft knitted & 0.59 & 155 & 19 & 15 \\
\hline Violet & weft knitted & 1.23 & 255 & 8 & 7 \\
\hline Grey-white & weft knitted & 0.81 & 204 & 19 & 12 \\
\hline Jeans & woven & 0.79 & 162 & 13 & 15 \\
\hline
\end{tabular}


(National Instruments) was mounted on the record player instead of the common arm in a 3D printed holder for different tips, as depicted in Figure 1, in a distance of $105 \mathrm{~mm}$ from the middle of the turntable. The lever with the counterweight (Figure 1b) lets the tip softly touch the fabric (distance of $0 \mathrm{~mm}$ ) so that the friction does not move the fabric, but a constant connection is ensured. The output voltage signals of the microphone were digitalised by the AD converter (sample frequency of $51.2 \mathrm{kHz}, 24 \mathrm{bits}$ ) and saved and evaluated by a self-written Matlab code. Generally, the sound is produced by friction between the textile fabric and tip.

Different pipettes and tubes from glass and plastics and a ballpoint pen refill (Figure 1c) were tested as tips. The plastic pipettes were found not to be stiff enough; their own bending caused undesired noise, which is why they were excluded after the first tests. The glass tubes, on the other hand, were not fine enough and impacted the textile fabrics too strongly.
Finally, a stainless-steel ballpoint pen refill without dye (no-name, refill diameter of $2.51 \mathrm{~mm}$, ball diameter of $1.5 \mathrm{~mm}$ ) was chosen for the main tests.

\section{Results and discussion}

Firstly, Figure 2 depicts exemplary time-domain results of measurements on the "red" sample (Figure 1a) on different time scales. Generally, the record player was set to $33 / \mathrm{min}$, i.e. $0.55 \mathrm{~Hz}$, meaning that one rotation takes $1.82 \mathrm{~s}$ (denoted by vertical black lines). Each measurement was performed during 6 full rotations, so that the values in the middle of the measurement duration are free from any possible bias due to starting and ending the rotational movement.

Starting with the complete measurement along 6 rotation cycles (Figure 2a), there are no regularities clearly visible. Examining exactly one rotation cycle (Figure 2b) results in approx. 5-7 minima
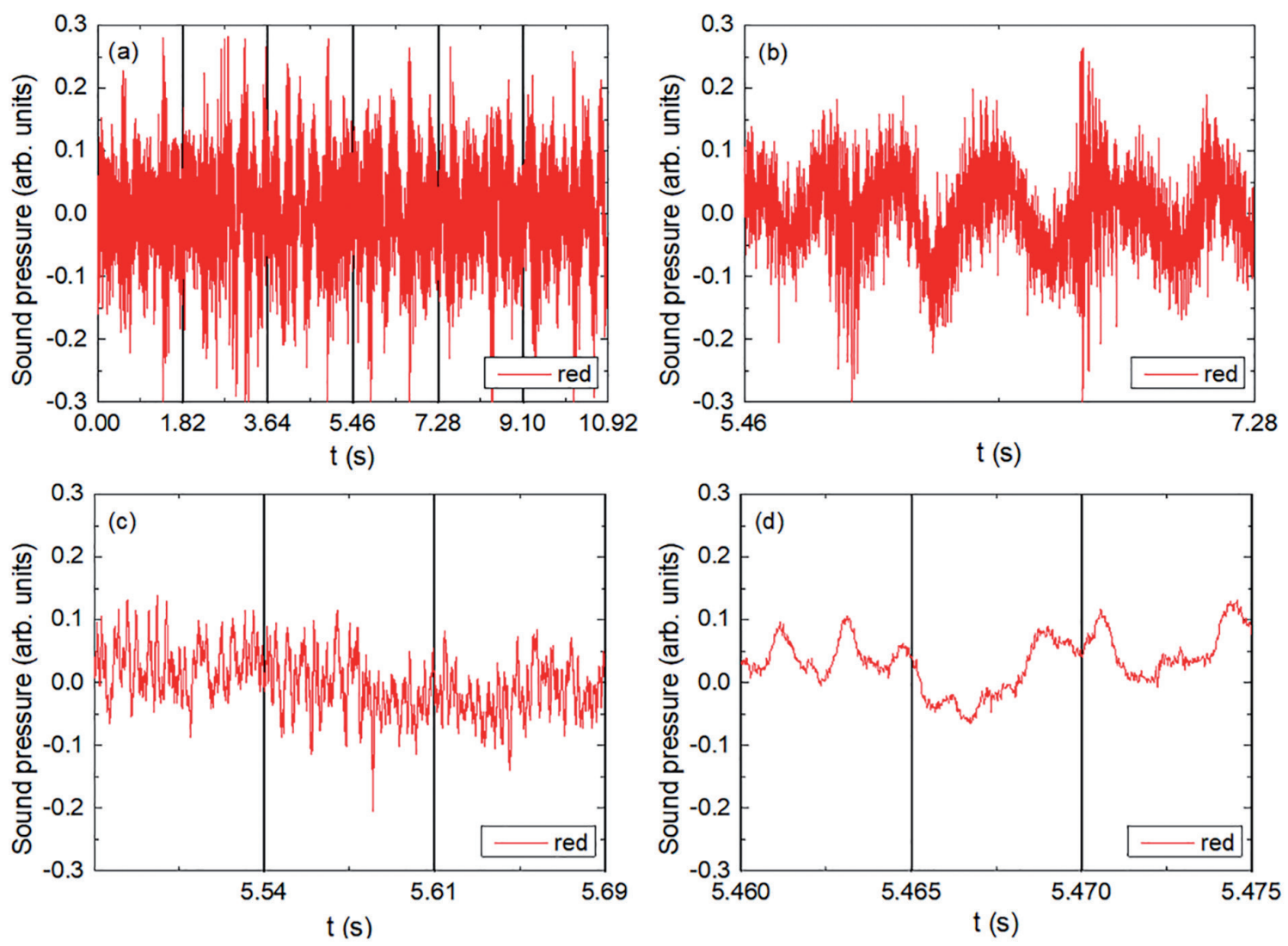

Figure 2: Measurements of time-dependent sound pressure of the red sample for different time scales: a) full measurement over 6 cycles, b) measurement during the $3 r d$ cycle, c) measurement during the first $45^{\circ}$ of the $3 r d$ cycle, and d) measurement during the first $3^{\circ}$ of the 3 rd cycle 
and maxima, depending on how exactly these are counted, with varying amplitudes and wavelengths. Generally, a fourfold anisotropy may be expected due to the symmetry of a knitted fabric, which is, however, not visible here.

Next, Figure $2 \mathrm{c}$ further decreases the time section under investigation, this time to an angle of $45^{\circ}$ between the first and last depicted results. Now, the short-time variations inside the longer ones, seen in Figure $2 \mathrm{~b}$, also become visible. Finally, the time is reduced to $\sim 0.015 \mathrm{~s}$, corresponding to an angle of $3^{\circ}$ which is depicted in Figure 2d. Here, the short-term variations become well visible, together with even shorter variations that can be attributed to noise.

These oscillations are still not harmonic, which obviously results from the steady rotation of the system, as opposed to a linear movement, in which threads should be passed in continuous durations.

Next, Figure 3 depicts sections of $3^{\circ}$ (corresponding to Figure 2d) of the other four fabrics. Here, we see clear differences, especially between the knitted and the woven fabric ("jeans"), while the coarsest knitted fabric ("violet") does not show such strong deviations from the others.

To understand these differences, it is supportive to compare the average numbers of yarns per centimetre with the measured frequencies. This is done here for the jeans woven fabric.

According to Table 1, this fabric has an average number of 14 yarns $/ \mathrm{cm}$, assuming that counting occurs along the orientation of the warp or weft yarns, which is not the case here. For a rough estimate, however, we can assume that the well-visible maxima and minima belong to crossing one yarn at a time, while some lateral sliding correlated with shifting a yarn may occur in the more noisy regions, e.g. in the left part of Figure $3 \mathrm{~d}$. From the radius of the circle, on which the ballpoint pen refill is moved (105 mm), a circumference of $660 \mathrm{~mm}$ can be calculated, which is measured within $1.82 \mathrm{~s}$. For the areas, in which measurement takes place more or less parallel to the warp or weft yarns, we can calculate a frequency of approximately 508 yarns/s, i.e. an expected time distances between subsequent maxima of approximately $2 \mathrm{~ms}$.
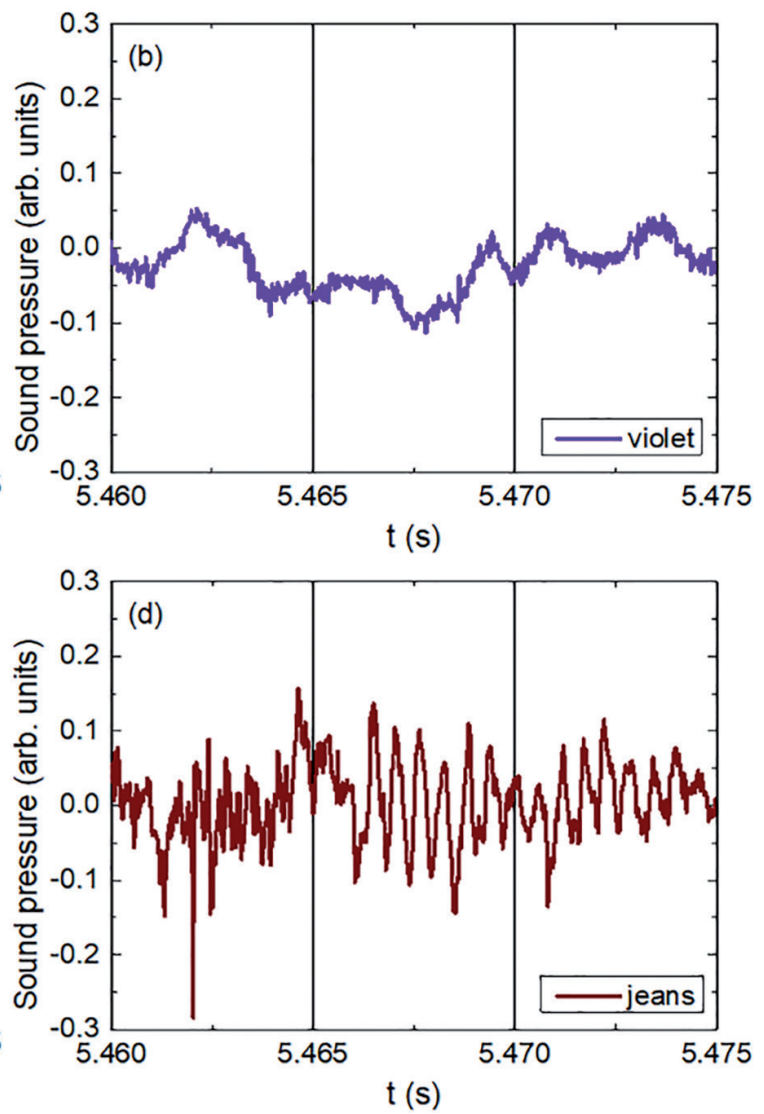

Figure 3: Measurements of time-dependent sound pressure of the other samples for identical durations: a) green, b) violet, c) grey-white, and d) jeans fabrics 

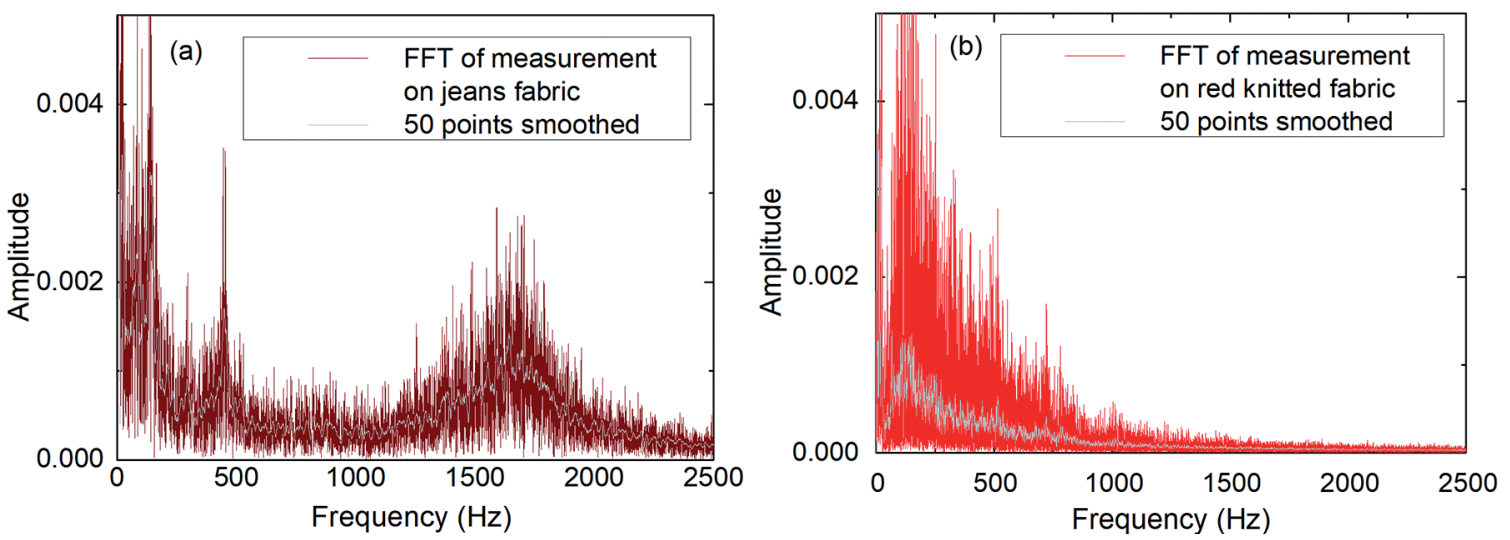

Figure 4: FFT spectrum of the full measurement on the jeans fabric (a) and the red knitted fabric (b)

For the right part of Figure 3d, a much smaller value of approximately $0.59 \mathrm{~ms}$ is calculated (i.e. 1690 $\mathrm{Hz}$ ), while in the left part as well as in other parts of the whole graph (not shown here), another time distance can be detected, i.e. approximately $2.1 \mathrm{~ms}$ $(470 \mathrm{~Hz})$. These values indicate that in general, the clear oscillations are correlated with the ballpoint pen refill crossing the yarns since both occur on the same time scale. However, a more sophisticated calculation is necessary to evaluate the warp and weft densities acoustically.

It must also be mentioned that the highly irregular oscillations of the knitted fabrics suggest finding better methods than manual estimations of the average wavelength, which would be a necessary prerequisite of correlating frequencies to structures. For this, typically a fast Fourier transform (FFT) is applied. Figure 4 clearly shows the FFT spectrum of the measurements on the jeans fabric and on the red knitted fabric, as originally calculated for the whole measurement duration of $10.9 \mathrm{~s}$ (6 rotation cycles) and smoothed over 50 points to suppress the noise. Two main frequencies are visible for the jeans fabric (Figure 4a): approximately $450 \mathrm{~Hz}$ and approximately $1650 \mathrm{~Hz}$, both quite near to the manually calculated frequencies for the jeans fabric. The smaller frequency, where a thinner and higher peak is visible, is apparently correlated to the ballpoint pen refill crossing a yarn, as calculated above, while the other peak is much broader and must thus be correlated with the ballpoint pen refill crossing yarns under other angles than $90^{\circ}$, resulting in crossing warp and weft yarns alternatingly and thus leading to higher frequencies. However, as mentioned above, a more sophisticated geometric model is necessary to fully understand all information available from such acoustic measurements.
The FFT of the measurement on the red knitted fabric (Figure $4 \mathrm{~b}$ ), however, shows only one clear peak around $150 \mathrm{~Hz}$ and some smaller peaks around $520 \mathrm{~Hz}, 720 \mathrm{~Hz}$ and $1010 \mathrm{~Hz}$. According to the above explained calculation, we would expect for this knitted fabric frequencies of approximately $690 \mathrm{~Hz}$ and $1090 \mathrm{~Hz}$ (if both yarns in a stitch are crossed) or $540 \mathrm{~Hz}$ (if a stitch is crossed near the head where only one yarn is detected), respectively. These expected frequencies fit to the small peaks in Figure $4 \mathrm{~b}$. Nevertheless, these peaks are not highly reliable due to the large background. Besides, the larger peak near $150 \mathrm{~Hz}$ remains unexplained.

An important factor to evaluate the value of such measurements is the reproducibility. It was addressed with measurements during 6 full rotation cycles. Figure 5 depicts results of subsequent measurements on the woven jeans fabric and on one of the knitted fabrics. A time was chosen where the woven fabric showed a change in the oscillation amplitude to enable comparison between subsequent rotation cycles. For the woven fabric (Figure 5a), the first curve is clearly lower and varying stronger due to the starting process of the measurement. The others all show a reduced amplitude in a similar range, spaced by one rotation (marked by the black arrow), and also other similarities. It should, however, be mentioned that textile fabrics are soft and not completely inelastic (even a woven fabric) and it is thus obvious that - opposite to a metal plate or similar - the positions measured will always vary slightly due to the interaction between the measurement tip and fabric. The measured frequencies, however, should be similar. FFT values for the short durations depicted here allow for only a rough estimation; nevertheless, the values depicted in Figure 5a are mostly similar, except the first rotation. 

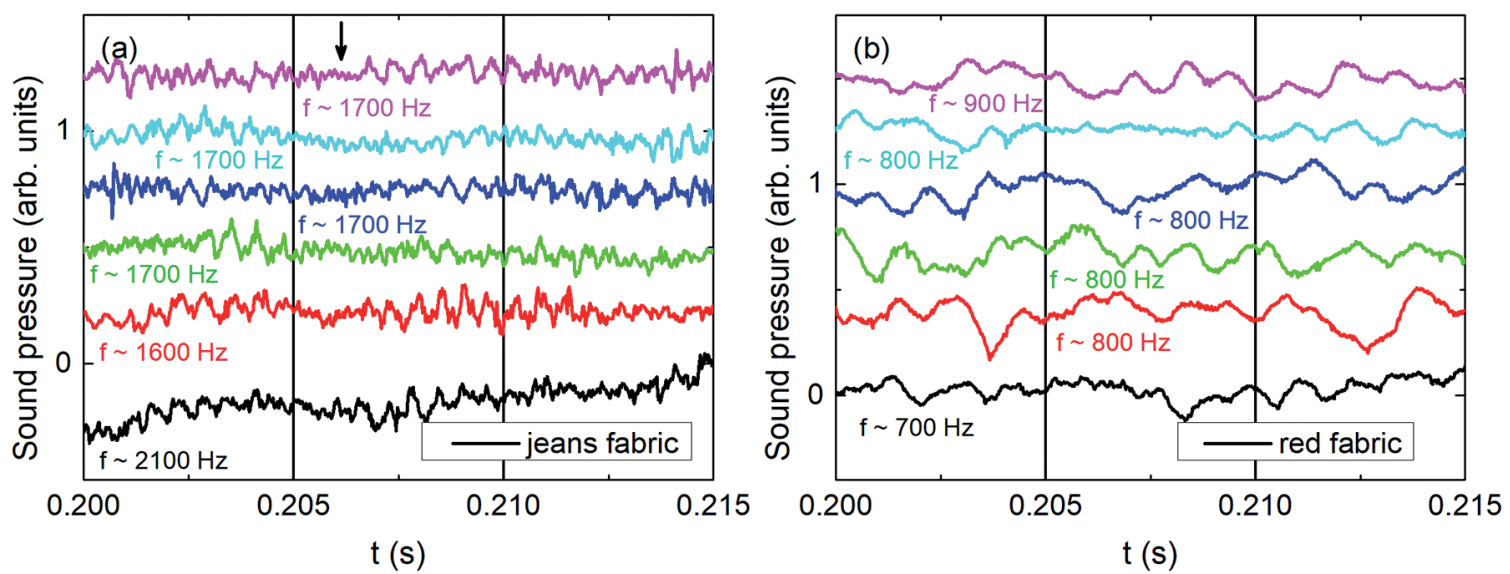

Figure 5: Time-dependent sound pressure measurements at identical positions for (black) first, (red) second, (green) third, (blue) fourth, (cyan) fifth and (magenta) sixth rotation. The lines are vertically offset for clarity by a constant value. Insets depict approximate frequencies, as calculated by FFT for the visible durations. Values are shown for jeans fabric (a) and for red knitted fabric (b).

The results for knitted fabrics are different. On the one hand, frequency measurements by FFT are even less exact here, while the measured frequencies are again similar. It is not possible, however, to find corresponding features in the measurements at the same position during different rotation cycles. Apparently, even a small pressure of the ballpoint pen refill is sufficient to move single threads in the stitches or elongate the knitted fabric so that in each rotation cycle a slightly different position of the knitted fabric is examined. We assume that these problems, which were already recognised in Figure 4 b, can be reduced if in the next version the tip is made flexible, e.g. in the form of an elastic metal strip with a fine, rounded tip fixed in the tip holder. Probably, similar to atomic force microscopy (AFM) where the cantilevers have to be chosen according to the samples under investigation and according to the exact questions to be answered, it is necessary to define different tips for samples of different surface roughness, yarn stiffness, hairiness, etc.

\section{Conclusion}

Acoustic measurements of different knitted and woven fabrics were performed rotating the textile fabrics on the turntable of a record player and measuring the sound of a ballpoint pen refill by a microphone. Time-domain and frequency-domain evaluations allow detecting frequencies for woven fabrics, which can be correlated with the yarn density. On the other hand, more information is contained in the FFT spectra that has to be evaluated carefully. For knitted fabrics, the soft yarns seem to be moved strongly by the ballpoint pen refill, resulting in highly irregular signals due to shifted yarns, which are crossed at random positions within a certain interval, which necessitate a more sophisticated experimental and/ or theoretical approach.

\section{Acknowledgment}

The authors would like to thank Nils Grimmelsmann and Joachim Waßmuth for their support in performing and evaluating the measurements, and Sönke Lück for lending them the microphone and AD-converter.

\section{References}

1. CAI, Zenong, LI, Xianhui, GAI, Xiaoling, ZHANG, Bin, XING, Tuo. An empirical model to predict sound absorption ability of woven fabrics. Applied Acoustics, 2020, 170, 1-8, doi: 10.1016/j. apacoust.2020.107483.

2. ATIENZAR-NAVARRO, R., BONET-ARACIL, M., GISBERT-PAYA, J., DEL REY, R., PICO, R. Sound absorption of textile fabrics doped with microcapsules. Applied Acoustics, 2020, 164, 1-9, doi: 10.1016/j.apacoust.2020.107285.

3. SEGURA ALCARAZ, Pilar, SEGURA ALCARAZ, Jorge Gabriel, MONTAVA SEGUI, Ignacio, BONET ARACILL, Mariles. Optimisation of the sound absorption of a textile material. Dyna, 2020, 95(3), 313-316, doi: 10.6036/9570. 
4. PAKDEL, Esfandiar, NAEBE, Maryam, KASHI, Sima, CAI, Zengxiao, XIE, Wanjie, YUEN, Anthony Chun Yin, MONTAZER, Majid, SUN, Lu, WANG, Xungai. Functional cotton fabric using hollow glass microspheres: focus on thermal insulation, flame retardancy, UVprotection and acoustic performance. Progress in Organic Coatings 2020, 142, 1-10, doi: 10.1016/j. porgcoat.2020.105553.

5. LI, Huiqin, ZHANG, Nan, FAN, Xiaodan, GONG, Jixian, ZHANG, Jianfei, ZHAO, Xiaoming. Investigation of effective factors of woven structure fabrics for acoustic absorption. Applied Acoustics, 2020, 161, 1-8, doi: 10.1016/j. apacoust.2019.107081.

6. HUGHES-RILEY, Theodore, DIAS, Tilak. Developing an acoustic sensing yarn for health surveillance in a military setting. Sensors, 2018, 18(5), 1-12, doi: 10.3390/s18051590.

7. YOKOI, M., NAKAI, M. The influence of random surface roughness on frictional noise. Bulletin of Japan Society of Mechanical Engineers, 1982, 25(203), 827-833, doi: 10.1299/jsme1958.25.827.

8. OTHMAN, M. O., ELKHOLY, A. H., SEIREG, A. A. Experimental investigation of frictional noise and surface-roughness characteristics. Experimental Mechanics, 1990, 30(4), 328-331, doi: 10.1007/BF02321499.

9. WANG, Pin-Ning, HO, Mig-Hsiung, CHENG, Kou-Bing, MURRAY, Richard, LIN, ChunHao. Study on the friction sound properties of natural-fiber woven fabrics. Fibres \& Textiles in Eastern Europe, 2017, 25(2), 34-42, doi: $10.5604 / 12303666.1228183$.

10. YI, E., CHO, G. Fabric-sound classification by autoregressive parameters. The Journal of
The Textile Institute, 2000, 91(4), 530-545, doi: $10.1080 / 00405000008659126$.

11. YI, Eunjou, CHO, Gilsoo. Fabric sound parameters and their relationship with mechanical properties. Textile Research Journal, 2000, 70(9), 828-836, doi: 10.1177/004051750007000911.

12. YI, Eunjou, CHO, Gilsoo, NA, Youngjoo, CASALI, John G. A fabric sound evaluation system for totally auditory-sensible textiles. Textile Research Journal, 2002, 72(7), 638-644, doi: 10.1177/004051750207200712.

13. KIM, Chunjeong, CHO, Gilsoo, NA, Youngjoo. Effects of basic weave differences in silk fabric and yarn type variations in satin weave on sound parameters. Textile Research Journal, 2002, 72(6), 555-560, doi: 10.1177/004051750207200616.

14. KIM, Chunjeong, CHO, Gilsoo, YOON, Hyesin, PARK, Shinwoong. Characteristics of rustling sounds created by the structure of polyester warp knitted fabrics. Textile Research Journal, 2003, 73(8), 685-691, doi: 10.1177/004051750307300805.

15. CHO, Soomin, CHO, Gilsoo, KIM, Chunjeong. Fabric sound depends on fiber and stitch types in weft knitted fabrics. Textile Research Journal, 2009, 79(8), 761-767, doi: 10.1177/0040517508099915.

16. PARK, Changsoon, CHO, Gilsoo. Analysis of acoustic characteristics of fabrics in terms of mechanical properties. Fibers and Polymers, 2012, 13(3), 403-410, doi: 10.1007/s12221-0120403-6.

17. YOSOUF, Khaldon, LATROCH, Hadj, SCHACHER, Laurence, ADOLPHE, Dominique C., DREAN, Emilie, ZIMPFER, Véronique. Frictional sound analysis by simulating the human arm movement. AUTEX Research Journal, 2017, 17(1), 12-19, doi: 10.1515/aut-2015-0033. 